\title{
An Analysis of the Perceptions on Academic Emotions and Emotional Experiences in English Language Teaching ${ }^{1}$
}

\author{
Ceyhun Yükselir \\ Osmaniye Korkut Ata University, Faculty of Science and Letters \\ Department of English Language and Literature, 80000 Osmaniye/TURKEY \\ E-mail: ceyhunyukselir@osmaniye.edu.tr; ceyhunyukselir@hotmail.com
}

Received: September 29, 2014 Accepted: November 3, 2014 Published: November 14, 2014

doi:10.5296/ijele.v2i2.6617 URL: http://dx.doi.org/10.5296/ijele.v2i2.6617

\begin{abstract}
The main purpose of this study is to investigate the perceptions of academic emotions and emotional experiences by the learners in English language teaching. To this respect, a questionnaire, Achievement Emotions Questionnaire (AEQ) prepared by Pekrun et al (2005) was administered to the EFL prep-class students of School of Foreign Languages at Atatürk University in 2011-2012 academic year. The parts of AEQ related to before, during and after learning and taking a part were included to find out the differences. However, this study only gives information about one positive emotion (enjoyment) and one negative emotion (anger) in before, during and after learning and taking a test, respectively. Finally, the results were analyzed and compared to find out the perceptions of the students in terms of academic emotions and emotional experiences.
\end{abstract}

Keywords: Academic emotions, Emotional experience, Achievement, Learning strategies

\footnotetext{
${ }^{1}$ This study was taken from $\mathrm{PhD}$ thesis. This study was also presented in the $1^{\text {st }}$ International Interdisciplinary Conference on Challenges in Language entitled "Language in Culture and Culture in Language - New Horizons", at Pantswowa Wyzsza Szkola Zawodowaw, Nowy Sącz / POLAND. This is the extended version of the proposal.
} 


\section{Introduction}

\subsection{What is Emotion?}

The term emotion has a significant place in educational psychology. Emotion and emotional regulation strategies can affect students' academic achievement and goals and also determine the processes that university students experience before, during and after learning, class and test. In the previous years, emotion or emotional experience was not intensively studied, but in recent years, a number of studies have been carried out to clarify emotions, emotional experience, academic emotions and achievement.

The etymological development of the word 'emotion' shows that it dates back to the $16^{\text {th }}$ century. The semantic notion underlying emotion - of applying 'physical movement' metaphorically to 'strong feeling' - is an ancient one: Latin used the phrase mōtusanimā, literally 'movement of the spirit', in this sense. Emotion itself is a post-classical Latin formation; it comes ultimately from Vulgar Latin exmovēre, literally 'move out', hence 'excite', a compound verb formed from the prefix ex- 'out' and moverre 'move' (source of English move). In French this became émouvoir, and English borrowed its derived noun émotion, but at first used it only in the literal sense 'moving, agitation' ('The waters continuing in the caverns ... caused the emotion or earthquake', Philosophical transactions of the Royal Society 1758) and the metaphorically extended 'political agitation or disturbance' (a sense now preserved only in émeute $\left(19^{\text {th }} \mathrm{c}\right.$.), another derivative of French émouvoir). It was not until the late 17 th century that the sense 'strong feeling' really came to the fore. The back-formation emote is a 20th-century phenomenon, of US origin. The definitions provided for the term emotion change enormously in both common sense and scholarly understandings. Although there is a common understanding which shows either one or more of four characteristics of emotion, namely; situational appraisals, action tendencies, bodily sensations, and expressive or display behaviors (Parkinson, 1995).

Pekrun (2006) defined emotions as "multi-component, coordinated processes of psychological subsystems including affective, cognitive, motivational, expressive, and peripheral physiological processes" (p. 316). According to Pekrun et al., (2002) emotions can enhance individuals' motivation and help them focus attention on the emotional state. Schutz $\&$ DeCuir (2002) pointed out that "the experience of an emotion arises from interpreting and evaluating both the emotional state and the context in which it occurs" (as cited in Webster, 2008).

Kelly (2004) wrote that emotions can be affected by individual's thoughts, ideas and behavior. Emotions play a crucial role with complement effect during education process. Oatley (2000) argued that the main function of emotion is to serve specific social goals - protection, affiliation and dominance that are made up of the foundation of society and so called human cooperation.

\section{Literature Review}

\subsection{Classification of Emotions}

According to (Pekrun and Hofmann, 1999; Pekrun, 2000), academic achievement was related 
to test anxiety. Several emotions determine the emotions which university students experience at university. In the experimental research conducted by Pekrun et al. (2002) nine different emotions were found effective in university students' academic achievements, physical and psychological situations and their thoughts. Consequently, these emotions were called as "academic emotions". Four of these emotions were described as positive emotions whereas five of them as negative emotions.

$\underline{\text { Positive Emotions }}$

1. Joy

2. Hope

3. Pride

4. Relief $\underline{\text { Negative Emotions }}$

1. Anger

2. Anxiety

3. Shame

4. Hopelessness

\section{Boredom}

In an educational environment, positive and negative emotions were made up of a complex process. To Kelly (2004), positive and negative emotions influenced university students' attention, motivation and limited their performance in an optimal way. Negative emotions decrease learners' academic achievements since they affect their concentration on the target subject, comprehension and all intellectual functions negatively. This kind of interaction has an important place in the course of education process. Thus, it is crucial for teachers and instructors to pay attention to the positive and negative emotions. It is clear that this situation influence students' motivation and academic achievement positively and also change their negative point of view into positive towards learning situations, classes, tests and teachers as well.

As mentioned above, if positive and negative emotions affect behavioral and cognitive processes in relation to motivation increasing academic achievement of students, it is crucial that positive emotions should be increased and negative emotions should be decreased in order to increase academic achievement. So, academic achievement can be said to be directly related to the encouragement or inspiration of the learners towards the course.

\subsection{Academic Emotions and Emotional Experiences}

There is a general consensus that emotions can be characterized by subjective and individual experience of particular ways. Despite the fact that emotions are complex and a considerable disagreement exists among theorists about its nature, there is an agreement that subjective experience is an important aspect of emotion, at least in humans. Many areas of psychology have enabled human beings to comprehend emotion, thus, among these areas; social psychology has been one of the most effective areas, especially in referring to the emotional experience.

Human beings are not independent of their experiences in their life. This is also valid for learning. In any time, the experiences of people have paved the way for reaching their goals or not. Experience is of paramount importance in education because it is directly related to the individual, human beings. The learner is evaluated within her/his own progress as both 
learning and experience are unique to the individual.

Learning and teaching are emotional as well as cognitive activities. Teaching and learning are emotional experiences occurring within the context of relationships. As a matter of fact, in the field of learning and teaching, emotional experiences may affect learners' moods and this influence can change from person to person. Taking these differences into consideration, we can say that emotional experiences play a vital role in learning and teaching. These experiences are properly dealt with in order to gain a full insight of the participants.

Students experience a variety of emotions in academic settings that influence their perceptions and behavior. The results obtained from the studies conducted by Pekrun, Goetz, Titz, and Perry (2002) show that academic emotions are significantly related to the students' motivation, learning strategies, cognitive resources, self-regulation, and academic achievement, and their findings display that affective and cognitive research in education should be regarded as improving the emotional diversity in academic settings by referring to various emotions experienced by learners. Emotions might influence students' achievement as well as their interest, engagement, and personality development, in addition to influencing the social aspect in courses and educational institutions (Pekrun, 2006).

In its broadest sense, academic emotions are the ones observed and experienced in an academic setting and context. As indicated by Pekrun et al (2002), there can be five situations related to the academic achievement: (a) attending class, (b) taking tests and exams, (c) studying or doing homework by oneself, (d) studying or doing homework in a learning group, and (e) other situations in which one is cognitively occupied with academic achievement (e.g. talking about an upcoming exam with a peer) (as cited in Goetz et al., 2003, p. 11).

The following schema shows the classification of academic emotions and takes the traditional criteria of valence (positive vs. negative) and activation (activating vs. deactivating) into consideration. This schema also evaluates the academic emotions according to these criteria. While valence can be thought as a bipolar dimension (positive vs. negative), activation can be made out as unipolar in nature, and shows the extent to which a given emotion is activating. Table 1 shows the corresponding $2 \times 2$ table in which academic emotions are defined. (Kleine, Goetz, Pekrun \& Hall, 2005).

Table 1. Classification of academic emotions

\begin{tabular}{|l|l|l|}
\hline \multicolumn{2}{|c|}{ Valence } \\
\hline Activation & Positive & Negative \\
\hline Activating & enjoyment & anxiety \\
\cline { 2 - 3 } & pride & anger \\
\cline { 2 - 3 } & hope & shame / fault \\
\hline \multirow{2}{*}{ Deactivating } & relief & boredom \\
\cline { 2 - 4 } & relaxation & hopelessness \\
\hline
\end{tabular}


In the classification of emotions, categories in academic emotions may be created as a distinct but by coinciding the concept that is a reflection of value and control mechanisms concerning to cognition and cognitive events.

Some of the academic emotions can be defined as follows:

Joy: This word refers to the emotion of great happiness and delight caused by something good or satisfying.

Pride: It is the state or feeling of proud.

Hope: As a desire of some good, accompanied with an expectation of obtaining it, or a belief that it is obtainable; an expectation of something which is thought to be desirable such as confidence; pleasing expectancy.

Enjoyment: The condition of enjoying anything such as pleasure or satisfaction, as in the possession or occupancy of anything; possession and use; as, the enjoyment of an estate.

Relief: As the easing or alleviation of a burden or distress, such as pain or anxiety.

Anxiety: As a state of uneasiness and apprehension especially for future concerns.

Shame: This word refers to the painful feeling which is caused by something dishonorable or ridiculous.

Hopelessness: It is a word referring to lack of hope; providing no hope.

Boredom: It is the state of being bored or tedium.

Anger: it is a strong feeling of displeasure or hostility towards others.

In Pekrun's social cognitive model, separate academic emotions are conceived as having specific effects on learning and achievement which are based on how they are sorted out within this conceptual schema. This model distinguishes between emotions that are positive-activating (enjoyment, pride, hope), positive-deactivating (relief, relaxation), negative activating (anxiety, anger, shame/guilt), and negative deactivating (boredom, hopelessness, disappointment). In view of achievement, one can mainly expect positive consequences from positive-activating emotions. Nevertheless, it remains unclear how negative-activating and positive-deactivating emotions influence learning and achievement (Kleine, Goetz, Pekrun \& Hall, 2005).

\section{Methodology}

\subsection{The Purpose of the Study}

One of the main purposes of this study is to investigate the emotional experiences of prep-class students of School of Foreign Languages at Atatürk University, Erzurum in order to figure out how academic emotions and emotional experiences in terms of enjoyment and anger can be perceived by Turkish university students. Eight emotions - enjoyment, hope, pride, anger, anxiety, shame, hopelessness and boredom - in learning and eight - enjoyment, hope, pride, anger, anxiety, shame, hopelessness and relief - in taking a test were assessed in three different situations before exam, during exam and after exam by using the related parts of the Achievement Emotions Questionnaire (AEQ). However, this study tries to give 
information about only one positive academic emotion (enjoyment) and one negative academic emotion (anger) in learning and taking a test in order to enable teachers and instructors to have an insight about the academic emotions in general.

\subsection{Participants}

The research sample consists of 215 university students in total, with 156 male and 59 female students studying at different faculties in 2011-2012 academic year. They were students attending the prep-course offered by the School of Foreign Languages at Atatürk University before their graduate or post-graduate courses. Within the sample, $36 \%$ of the students study in the Department of Mechanical Engineering, 21\% of them study in the Department of Chemical Engineering, $21 \%$ of them study in the Department of Electrical and Electronic Engineering, $14 \%$ of them study in the School of Tourism and Hotel Management, $7 \%$ of them study in the Department of Chemistry and 1\% of them study in the Department of Civil Engineering. At the beginning of the study, the students were informed about this study and its importance. In addition, consent for all of the research was taken before the application.

\subsection{Data Collection Instruments}

As mentioned in the previous parts, a questionnaire, the Achievement Emotions Questionnaire (AEQ) by Pekrun, Goetz and Perry (2005) was used to collect the data of this study. This questionnaire consists of 196 statements in total, including learning, taking a test and class parts, however, 152 items related to learning and taking a test were used to collect data. The items in the questionnaire were translated into Turkish in order to enable the students to understand the items properly. The Achievement Emotions Questionnaire (AEQ) is a multidimensional self-report instrument which is designed to evaluate college students' achievement emotions. It is based on a program of quantitative research that examined students' emotions experienced in academic achievement situations.

\section{Results and Discussion}

In the following paragraphs, I would like to show briefly some striking findings obtained from the study.

In this study, 7 different statistical analyses were used in the data analysis. The analyses were computed using software package SPSS 16.0. The statistical significance level was set at $\mathrm{p}=0.05$. These analyses were given as follows:

1. Percentage

2. Frequency

3. Arithmetic mean

4. Standard deviation

5. Kruskal-Wallis analysis

6. Student's t-test

7. Dunnett's T3 post-hoc test

Student's t-test was used for paired samples to determine if there is a difference among scores 
of university students with respect to Enjoyment Before, During and After Learning and the results are shown in Table 2.

Table 2. Findings on differences among scores of university students with respect to enjoyment before, during and after learning

\begin{tabular}{|l|l|l|l|l|l|}
\hline & $\mathrm{N}$ & $\mathrm{X}$ & $\mathrm{S} . \mathrm{s}$. & $\mathrm{t}$ & $\mathrm{P}$ \\
\hline Enjoyment Before Learning & 215 & 2.69 & 1.08 & \multirow{2}{*}{3.389} & \multirow{2}{*}{0.001} \\
\hline Enjoyment During Learning & 215 & 2.44 & 0.53 & & \\
\hline Enjoyment Before Learning & 215 & 2.69 & 1.08 & \multirow{2}{*}{5.762} & \multirow{2}{*}{0.000} \\
\hline Enjoyment After Learning & 215 & 2.21 & 0.69 & & \\
\hline Enjoyment During Learning & 215 & 2.44 & 0.53 & \multirow{2}{*}{0.396} & 0.000 \\
\hline Enjoyment After Learning & 215 & 2.21 & 0.69 & & \\
\hline
\end{tabular}

As seen on Table 2, the t-values are statistically significant $(\mathrm{p}<0.05)$ regarding the differences among scores of university students with respect to Enjoyment Before, During and After Learning. These findings have indicated that there are differences among scores of university students with respect to Enjoyment Before, During and After Learning.

The results show that the arithmetic mean for Enjoyment Before Learning in university students is 2.69, which is greater than the arithmetic mean for Enjoyment During Learning, which is 2.44 .

Moreover, the results indicate that the arithmetic mean for Enjoyment Before Learning is 2.69, which is greater than the arithmetic mean for Enjoyment After Learning, which is 2.21.

As it is understood from the table, the arithmetic mean for Enjoyment During Learning in university students is 2.44 , which is greater than the arithmetic mean for Enjoyment After Learning, which is 2.21 .

All these findings indicate that Enjoyment Before Learning is at the highest level when compared to Enjoyment During Learning and Enjoyment After Learning and Enjoyment After Learning is at the lowest level.

Table 3. Findings on the differences among scores of university students with respect to enjoyment before, during and after taking a test

\begin{tabular}{|c|c|c|c|c|c|}
\hline & $\mathrm{N}$ & $\mathrm{X}$ & S.s. & $\mathrm{T}$ & $\mathrm{P}$ \\
\hline Enjoyment Before Taking a Test & 215 & 2.81 & 0.66 & \multirow{2}{*}{-0.473} & \multirow{2}{*}{0.637} \\
\hline Enjoyment During Taking a Test & 215 & 2.84 & 0.71 & & \\
\hline
\end{tabular}




\begin{tabular}{|l|l|l|l|l|l|}
\hline Enjoyment Before Taking a Test & 215 & 2.81 & 0.66 & \multirow{2}{*}{5.715} & \multirow{2}{*}{0.000} \\
\cline { 1 - 4 } Enjoyment After Taking a Test & 215 & 2.43 & 0.78 & & \\
\cline { 1 - 4 } Enjoyment During Taking a Test & 215 & 2.84 & 0.71 & \multirow{2}{*}{5.873} & 0.000 \\
\cline { 1 - 4 } Enjoyment After Taking a Test & 215 & 2.43 & 0.78 & & \\
\hline
\end{tabular}

Table 3 demonstrates that the $t$-values are statistically significant $(p<0.05)$ regarding the differences among scores of university students with respect to Enjoyment Before, During and After Taking a Test but they are not statistically significant Before and During Taking a Test $(\mathrm{p}>0.05)$. These findings have demonstrated that there are differences among scores of university students with respect to Enjoyment Before, During and After Taking a Test. All these findings have demonstrated that Enjoyment is at the highest level in university students During Taking a Test. However, it is at the lowest level After Taking a Test.

Table 4. Findings on the differences among scores of university students with respect to anger before, during and after learning

\begin{tabular}{|c|c|c|c|c|c|}
\hline & $\mathrm{N}$ & $\mathrm{X}$ & S.s. & $\mathrm{t}$ & $\mathrm{P}$ \\
\hline Anger Before Learning & 215 & 2.39 & 0.76 & \multirow{2}{*}{-0.263} & \multirow{2}{*}{0.792} \\
\hline Anger During Learning & 215 & 2.41 & 0.84 & & \\
\hline Anger Before Learning & 215 & 2.39 & 0.76 & \multirow{2}{*}{0.531} & \multirow{2}{*}{0.596} \\
\hline Anger After Learning & 215 & 2.35 & 1.15 & & \\
\hline Anger During Learning & 215 & 2.41 & 0.84 & \multirow{2}{*}{0.780} & \multirow{2}{*}{0.436} \\
\hline Anger After Learning & 215 & 2.35 & 1.15 & & \\
\hline
\end{tabular}

Table 4 shows that the t-values are not found statistically significant $(p>0.05)$ regarding the differences among scores of university students with respect to Anger Before, During and After Learning. These findings have demonstrated that there are not any differences among scores of university students with respect to Anger Before, During and After Learning. All these findings have demonstrated that scores of Anger Before, During and After Learning are similar.

Table 5. Findings on the differences among scores of university students with respect to anger before, during and after taking a test

\begin{tabular}{|l|l|l|l|l|l|}
\hline & $\mathrm{N}$ & $\mathrm{X}$ & S.s. & $\mathrm{t}$ & $\mathrm{P}$ \\
\hline Anger Before Taking a Test & 215 & 3.09 & 0.84 & 4.526 & 0.000 \\
\hline
\end{tabular}




\begin{tabular}{|c|c|c|c|c|c|}
\hline Anger During Taking a Test & 215 & 2.75 & 0.94 & & \\
\hline Anger Before Taking a Test & 215 & 3.09 & 0.84 & \multirow{2}{*}{6.688} & \multirow{2}{*}{0.000} \\
\hline Anger After Taking a Test & 215 & 2.64 & 0.82 & & \\
\hline Anger During Taking a Test & 215 & 2.75 & 0.94 & \multirow{2}{*}{1.611} & \multirow{2}{*}{0.109} \\
\hline Anger After Taking a Test & 215 & 2.64 & 0.82 & & \\
\hline
\end{tabular}

Table 5 demonstrates that the t-values are statistically significant $(p<0.05)$ regarding the differences among scores of university students with respect to Anger Before, During and After Taking a Test whereas the t-values for Anger During Taking a Test and Anger After Taking a Test are not statistically significant $(p>0.05)$. These findings have demonstrated that there are differences among scores of university students with respect to Anger Before, During and After Taking a Test. All these findings Show that anger before taking a test in university students is at the highest level, however anger after taking a test is at the lowest level. However, anger before taking a test in university students is at the highest level whereas anger after taking a test is at the lowest level.

\section{Conclusions}

Based on the results, we can say that the participants are more prone to be stressful before taking a test rather than after a taking a test. It is found out that Enjoyment Before Learning is at the highest level when compared to Enjoyment During Learning and Enjoyment After Learning and Enjoyment After Learning is at the lowest level. This suggests that learners may not be eager to learn a foreign language at times and this can stem from the difficulties of learning a new language in relation to grammatical structures, vocabulary etc. These findings can be helpful to instructors and teachers in helping their learners grasp the emotional experiences that adapt those best to an academic setting. The results obtained from this study can also be helpful to learners increasing their perceptions of their academic emotions and emotional experiences. Results of the study can enable almost all learners to become more conscious in their learning and their ability to take a test. This study also shows that EFL prep-class students have different approaches to learning and taking a test. In other words, their experiences and feelings in the course of before, during and after learning and taking a test can change from person to person. As a result of this, it is essential that the learners should be observed well with regard to their emotions and it is important to determine the approaches about learning in harmony with the academic emotions and experiences. Instructors and teachers should take the learners' individual emotional experiences and approaches into account while preparing and presenting teaching materials.

\section{References}

Diener, E. (2000). Subjective Well-being. The Science of Happiness and a Proposal for a National Index. American Psychologist, 55(1), 34-43.

Goetz, T., Zirngibl, A., Pekrun, R., \& Hall, N. (2003). Emotions, learning and achievement 
from an educational psychological perspective. In P. Mayring \& C. V. Rhoeneck (Eds.), Learning and emotions: The influence of affective factors on classroom learning (pp. 9-28). Frankfurt am Main: Peter Lang.

Kelly, W. (2004). Academic Emotions. Teaching at Trent, 6(3), 2-3.

Kleine, M., Goetz, T., Pekrun, R., \& Hall, N. (2005). The Structure of Students' Emotions Experienced during a Mathematical Achievement. International Review of Mathematical Education, 37, 221-225.

Oatley, K. (2000). The sentiments and beliefs of distributed cognition. In S. Bem (Ed.), Emotions and beliefs: How feelings influence thoughts (pp. 78-107). Cambridge: Cambridge University Press.

Parkinson, B. (1995). Ideas and realities of emotion. London: Routledge.

Pekrun, R., Goetz, T., Titz, W., \& Perry, R. P. (2002). Academic Emotions in Students' Self-regulated Learning and Achievement: A Program of Qualitative and Quantitative Research. Educational Psychologist, 37(2), 91-105.

Pekrun, R., Goetz, T., \& Perry, R. P. (2005). Achievement emotions questionnaire (AEQ). user's manual. Munich, Germany: Department of Psychology, University of Munich.

Pekrun, R., \& Hofmann, H. (1999). Lern-und Leistungs emotionen: Erste Befude eines Forschungs programms (Emotions in learning and achievement: First results of a program of research). In R.Pekrun \& M.Jerusalem (Eds.), Emotion, motivation und leistung, (pp.247-267). Göttingen, Germany: Hogrefe.

Pekrun, R. (2006). The Control-value Theory of Achievement Emotions: Assumptions, Corollaries, and Implications for Educational Research and Practice. Educational Psychology Review, 18, 315-341.

Pintrich, P. R., Smith, D. A. F., Garcia, T., \& McKeachie, W. J. (1991). A manual for the use of the Motivated Strategies for Learning Questionnaire (MSLQ).Ann Arbor: University of Michigan, National Center for Research to Improve Postsecondary Teaching and Learning.

Webster, E. (2008). The Emotional Experiences of University Students: Exploring the Role of Achievement Emotions in Self-regulated Learning. In Schutz, P. A. \& DeCuir, J. T. (2002). Inquiry on Emotions in Education. Educational Psychologist, 37(2), 125-134.

\section{Copyright Disclaimer}

Copyright for this article is retained by the author(s), with first publication rights granted to the journal.

This is an open-access article distributed under the terms and conditions of the Creative Commons Attribution license (http://creativecommons.org/licenses/by/3.0/). 